\title{
Study of the Present Situation of Architectural Protection in Taizhou Historic district of Zhejiang Province-Take Haimen Old Street as an Example
}

\author{
Li Ailin ${ }^{1, a^{*}}$ \\ ${ }^{1}$ Civil and Architectural Engineering, University of Jinan, Shizhong District, Jinan City, Shandong Province, PRC
}

\begin{abstract}
Taizhou is one of the important port cities and trade centers in Zhejiang Province in Chinese history. The traditional buildings retained in its historic districts have not only conformed to the development of the times, but also witnessed the local historical changes and finally formed their own unique local characteristics. The paper takes Haimen Old Street in a good condition of protection as the research object, conducts a comprehensive investigation on the protection status of modern architectures in the Old Street, and deeply explores the spatial forms and architectural features of the buildings. After investigation, it was found that Haimen Old Street has a good architectural shape and characteristics after undergoing conservation and restoration work, which can be said to be a model of architectural protection in eastern Zhejiang. This survey can provide evidence and suggestions for the protection of buildings in historical districts in Zhejiang, so as to achieve the purpose of inheriting the regional culture of Taizhou's characteristic buildings.
\end{abstract}

\section{Introduction}

There are still many traditional districts and folk buildings with important historical value in Taizhou city, most of which were built in the late Qing Dynasty and early Ming Dynasty. These historic districts and buildings have inherited the folk culture of Taizhou and carried the memory of the local residents of the city, such as Taizhou Jia Zhi Old Street and Haimen Old Street. Protecting them is of great significance to the inheritance of urban cultural heritage. Unfortunately, some districts have been simply transformed as tourism resources, and the focus of protection only stays in the modeling level of the building. Its original spatial form and community context have been destroyed in the process of reconstruction. In order to provide a basis for the protection of traditional historical districts in eastern Zhejiang, this article conducts a comprehensive investigation on the protection status of Haimen Old Street. The architecture in Taizhou Haimen Old Street contains different styles of architecture that can reflect the local historical changes, and its spatial form and architectural feature still retain the local characteristics. An in-depth study of the current situation and characteristics of its architectural protection can better promote the continuation and inheritance of traditional architecture and regional culture in modern society.

\section{Overview of Haimen Old Street}

\subsection{Historical Changes of the Old Street}

Haimen Old Street is located in Jiaojiang District, Taizhou City in the central coastal area of Zhejiang Province. Jiaojiang, formerly known as Haimen on the west coast of the East China Sea, is the sea gateway of Taizhou. Back in the Ming Dynasty, it used to be an important military base where the Haimen Fortress was built, which was how the embryonic form of the old Haimen initially took shape. Haimen was also a port city. After the opening of the port of Jiaojiang in the late Qing Dynasty and the beginning of the Republic of China, the trade exchanges and commercial development at the port flourished. Haimen once became the trade center of the Taizhou region, and was even called "Little Shanghai".

Haimen Old Street was rebuilt by monks at Jiaoji Temple in the Qing Dynasty and renamed "Daotou New Street". In the twenty-fourth year of Guangxu Reign in the Qing Dynasty (1898), Haimen began to open to trade, and on the old street a various of shops were opened and gathered a large number of merchants, among which some successful businessmen began to buy a lot of land for rent or operation ${ }^{[1]}$. There were also some Haimen people who had gone to Shanghai to make a living and introduced the style of European architecture to Haimen after getting rich. Therefore, the architectural style of the Old Street is varied, including Ming and Qing architecture, European architecture and Republic of

\footnotetext{
* Corresponding author: ${ }^{2} 2461620603 @ q q . c o m$
} 
China architecture, which displays the architectural styles of different eras.

\subsection{Present Situation of the Old Street}

Haimen Old Street was originally 470 meters long and currently 225 meters long. The street runs north-south, reaching Renmin Road in the south and Dongsheng Street in the north. About six to eight meters wide, it's mostly paved with slabs of stone. At the south end of the Old Street is the bridgehead, which is connected to the prosperous street corner. At the north end of the street is the Yangfu Temple, and there is an archway with the words "Haimen Guan" at its entrance. Haimen Old Street is a historic district full of Taizhou regional characteristics, and the government has attached great importance to its protection work, so the Old Street has been well protected. The original spatial forms and functions of the buildings in the streets and alleys have continued, which can still meet the needs of the residents living and doing business in the district. The local government has tried to keep as many old buildings as possible, repaired structurally unstable buildings as well as meticulously copied and replaced the buildings' dilapidated components so that the buildings in the street still retain their original features.

\section{Types of Spatial Forms of Haimen Old Street}

\subsection{External functions and spaces of the street}

Haimen Old Street is a well-preserved traditional historic district in Taizhou area. The buildings in the Old Street have borne a lot of functions in the process of the continuous development of the city. Meanwhile, its functions also affect the space shaping in the district to produce different street space forms, and the relationship between them is very close.

\subsubsection{Functions of the street}

The Old Street covers the functions of trade, traffic, residence and assembly. A large number of shops are gathered on both sides of the street to perform commercial functions. The road itself can play the function of traffic. Meanwhile, the upper layer and backyard of the shops along the street are living spaces. Such traditional courtyard houses where "upstairs dwelling and downstairs store" and "front store and backyard dwelling" can be seen are the main residential forms of the local residents. In addition, the open space near Yangfu Temple at the northern end of the Old Street also provides a venue for residents to hold cultural activities.

\subsubsection{The scale and shape of the street}

The linear street space is the basic space of the traditional district, and it is the key area of the life of merchants and residents. Under the influence of functions, the road scale of the Old Street changes constantly and finally develops into a form that fits the needs of users. The width of the main road with commerce as the main function is 4-6 meters, and most of the buildings on both sides of the street are two-story ones with a height of more than 6-7 meters. The aspect ratio of the road is about 0.75 , which is close to the scale that can give people a sense of intimacy and comfort. The main street has been properly broadened in front of Jiaojiang Calligraphy and Painting Academy and Yangfu Temple, and the street space has rich twists and turns, and there is a square at the end of the street to meet the needs of cultural activities and crowd gathering. In addition, as branches of the main street, a number of alleys are even narrower and deeper, which connect the side doors of the house or lead to other streets for natural transition of a commercial space to a residential one. Buildings in traditional historic districts are tightly spaced, and the scale of outdoor space nodes is also small. It is the street space that connects these spatial sequences with rich changes into a unified whole.

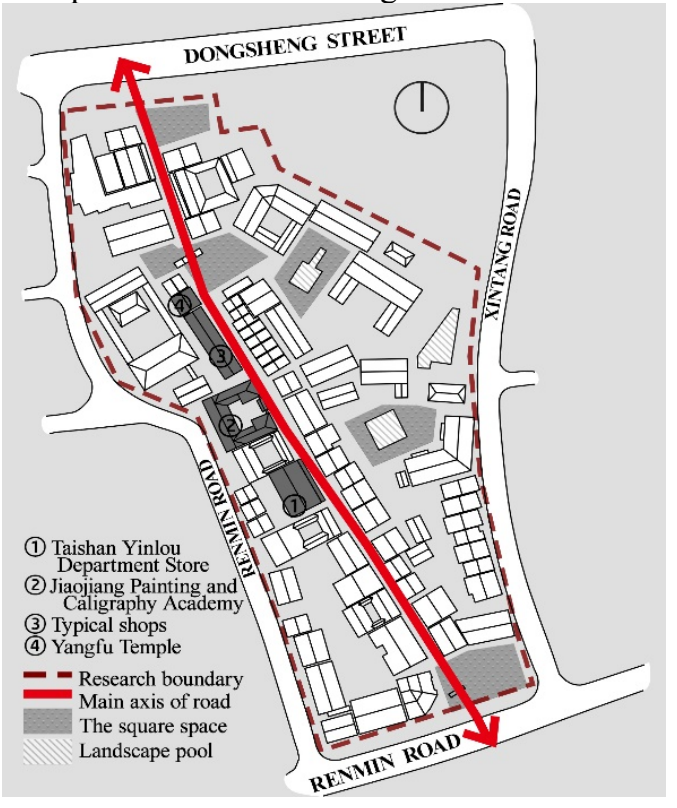

Fig. 1. Spatial distribution of Haimen Old Street

\subsection{Types of Internal Space in the Building}

The spatial form of the street can in turn affect the space and function of buildings. The scale of buildings in the Old Street is small, and each building will permeate each other in function. According to different use functions and space types, the existing buildings in the district can be divided into three types for detailed analysis: traditional shops along the street, traditional courtyard houses and in-wall shops with western style.

\subsubsection{Traditional shops along the street}

The traditional shops are located on both sides of the streets of the Old Street. Most of these buildings are commercial buildings where "upstairs dwelling and downstairs store" and "front store and backyard dwelling" can be seen. The number of building floors is mostly two 
floors, and their opening space is small and deep, and some shops are similar in shape and structure to traditional courtyard houses. What is shown in the picture is a typical "upstairs dwelling and downstairs store" traditional shop with three rooms and five beams. It uses the wooden frame as the load-bearing system and uses the beam-column structure to support the building so that the house remains upright while walls fall. So the walls can be arranged freely to divide the space according to their different functions ${ }^{[2]}$. The first floor of the building is commercial space, and the second floor is residential space. There is also some storage space at the rear of the building on the first floor. A larger shop building has storage space with access to the back street or another residential building.

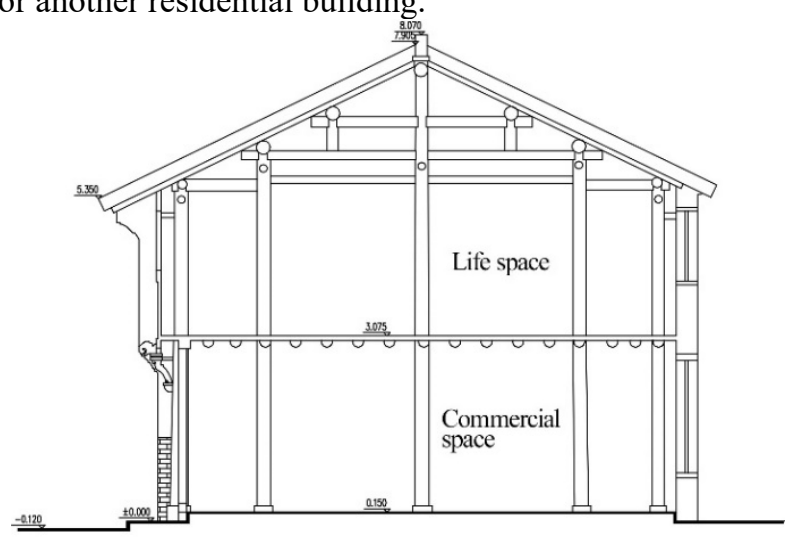

Fig. 2. Typical space of traditional shops

The second floor of some shops along the street has protruding floors or railings, which not only increases the area of living space, but also gives the first floor some grey space to attract pedestrians to stop or enter the shop. Yangfu Temple, which is similar in shape and structure to a shop, uses a colonnade to form a gray space, which makes the building space more solemn and formal. The shop construction along the street of the Old Street can basically meet the basic needs of the residents' business operation and daily life in space.

\subsubsection{Traditional courtyard houses}

There are many types of plane layouts for Taizhou traditional residential houses. In addition to the long strip residential houses, most of which are trilateral courtyards, there are also a small number of quadrangle courtyards in Haimen Old Street. Residential houses and shops use brick and wood structure to bear the load, and mostly use blue bricks to build cavity wall as external walls, while the wall base is filled with wool stone at the bottom ${ }^{[3]}$.

Trilateral courtyard is a typical representative of Taizhou residential house. Different from the well-ordered Beijing quadrangle courtyard, its layout is more flexible and natural. The three principal rooms of the type of residential house are located in the middle of the house facing south, with a hall in the middle and bedrooms on both sides. The east and west sides of the principal room are wing rooms facing the inner courtyard. Take No. 49 mansion in Haimen Old Street as an example. It is now converted to Jiaojiang Calligraphy and Painting Academy for exhibition. It is a small trilateral courtyard whose door faces the courtyard surrounded by the wing rooms on both sides and the open principal house. In terms of spatial layout, the division of the internal and external space of the house is not clear. In addition to the courtyard door, the wooden door of the wing room on the first floor can be opened directly to the street, which has a strong extroversion. There is also obvious permeability between different spaces on the second floor. The double-height space left in the center of the principal room and the overhanging corridor form a zigzag porch. No other room is completely separated by the wall except the wing rooms, and the rooms facing the inner courtyard and the street have a large number of open windows with direct views of the inner courtyard and the street, and sight accessibility is very strong. Therefore, the spaces on the first floor and the second floor as well as the interior and outdoor spaces of the building permeate each other.

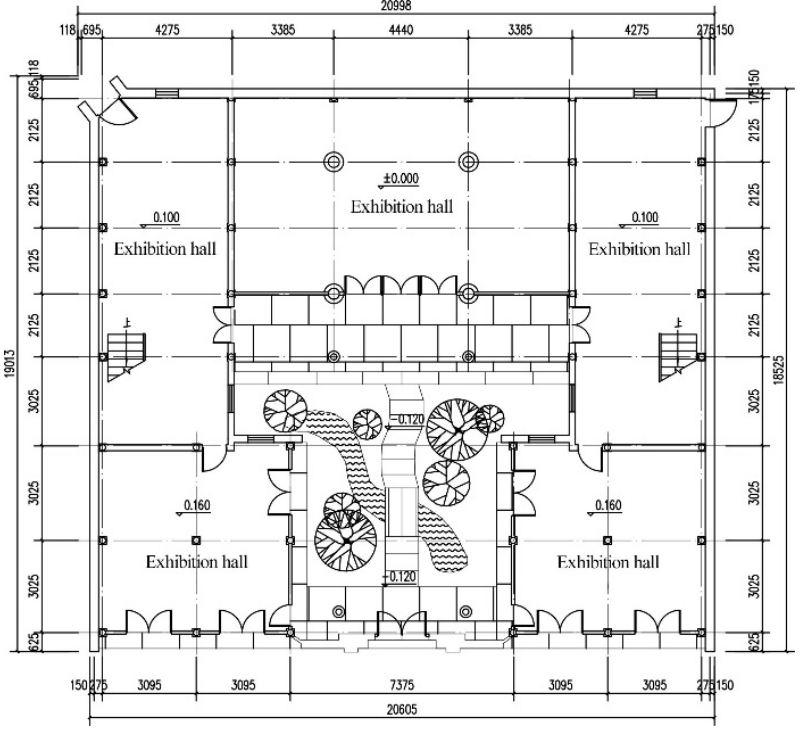

Fig. 3. The first floor of Jiaojiang Painting and Calligraphy Academy

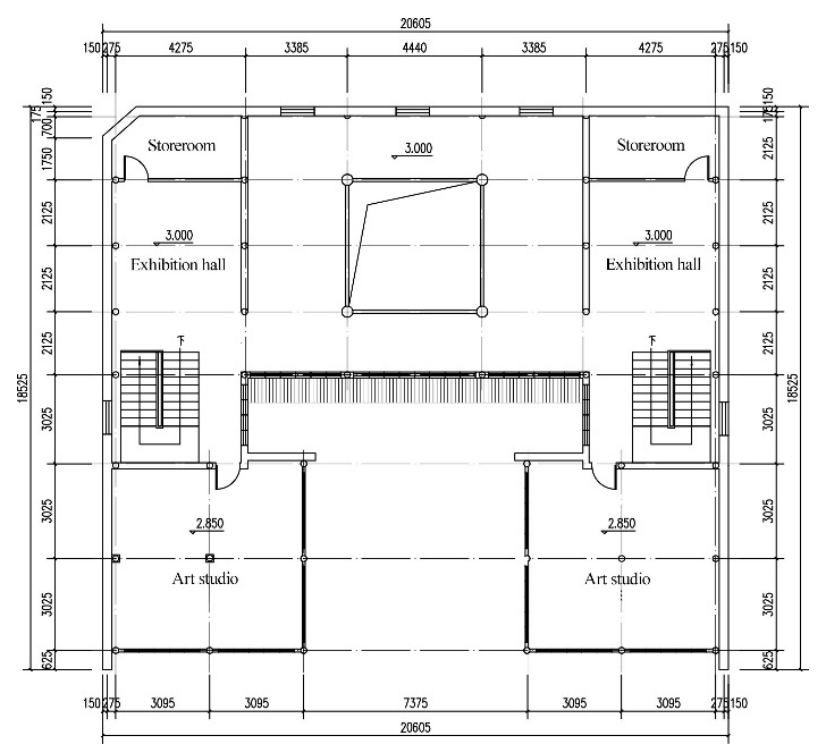

Fig. 4. The second floor of Jiaojiang Painting and Calligraphy Academy 
Moreover, the courtyard space of traditional courtyard houses also has strong local characteristics, and a large number of green plants, small bridges and flowing water are arranged in the small space. Different from the street life outside the house, the delicate and unique scenery inside the house stands on its own. Through the courtyard door one can see that the courtyard scenery and buildings complementary to each other. In addition to meeting the needs of lighting and ventilation, the inner courtyard can also communicate the internal private space and the external open space of the building, which enhances the accessibility of the space and the possibility of communication between neighbors.

\subsubsection{In-wall shops with western style}

After Taizhou opened the port, the new buildings in Haimen Old Street built by Taizhou residents, who had become rich in Shanghai and returned to the Old Street, had a very obvious western style. In terms of spatial layout, these buildings are similar to, and yet different from the local Stone Gate buildings in Shanghai. The buildings of Stone Gate adopt the traditional trilateral courtyard in shape and structure, while the western-style architecture in the Old Street is traditional Chinese shop with a western-style building facade, which introduces the "in-wall shop" building with the local characteristics of Taizhou.

The most representative "in-wall shop" building in the Old Street is Taishan Silver House, which was built in the Republic of China and mainly engaged in selling gold and silver wares and all kinds of imported foreign goods. The height of the exterior wall with both Chinese and Western styles in front of the Silver House is higher than that of the whole building, which forms a strong contrast with the internal Chinese façade and separates the interior from the exterior. Another major feature of the "in-wall shop" building is the patio. Different from the inner courtyard and the outer patio of the buildings of Stone-ringed Doors, most of the in-wall shops use the inner patio. The two patios in the Silver House are located in the main body of the building. One patio is the small patio between the outer facade and the inner facade, and directly below it is the reception of the Silver House, which is mainly used for lighting. The other one is the inner patio located in front of the staircase at the rear of the building, which can provide lighting for the interior of the building. The space layout of the in-wall shop building allows the house owners to enjoy a secluded space in the busy city and realizes harmony between the shops at the front and the living spaces in the back.

\section{Characteristics of Old Street Architecture}

The architectural style of Haimen Old Street is diverse, and the traditional shops and residential houses have the local characteristics of eastern Zhejiang Province, while the in-wall shop has the style of European Baroque. The facade style of the Old Street buildings is gradually transitioning from Chinese style to western style along the bridgehead to the river embankment, and its architectural features reflect the changes in Taizhou's modern history.

\subsection{Facade of Traditional Chinese Style Architecture}

The street shops and traditional courtyard houses in Haimen Old Street are traditional Chinese-style buildings with obvious regional characteristics of Taizhou. The street front of the Old Street is mostly in a straight linear shape, and the vertical facade of the building is a three-stage facade composed of roof, roof body and platform base. Yangfu Temple, which is similar in shape and structure to a shop, also adopts such a form. Some shops have overhanging floors or railings on the second floor to form a balcony. The form of the roof is generally gabbled roof, which can be divided into single eaves and double eaves. Many of the traditional residential houses also have waist eaves, forming the facade style of two-story one-eave and two-story two-eaves.

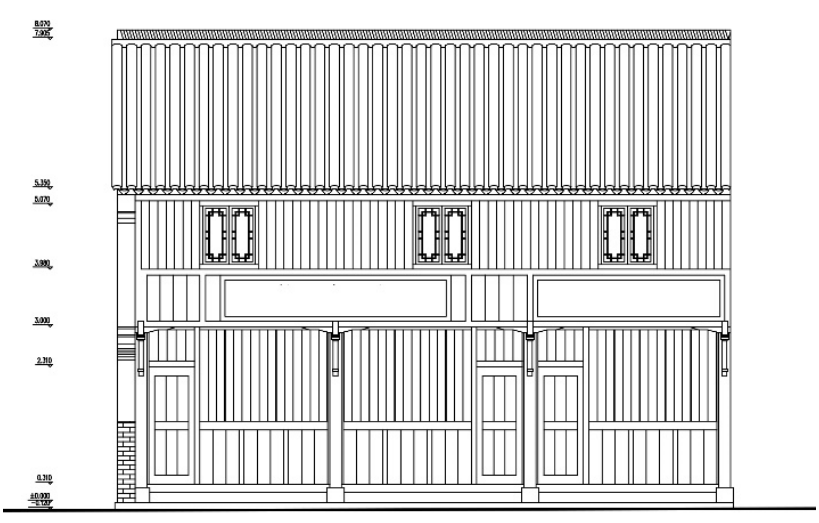

Fig. 5. Facade of traditional shops

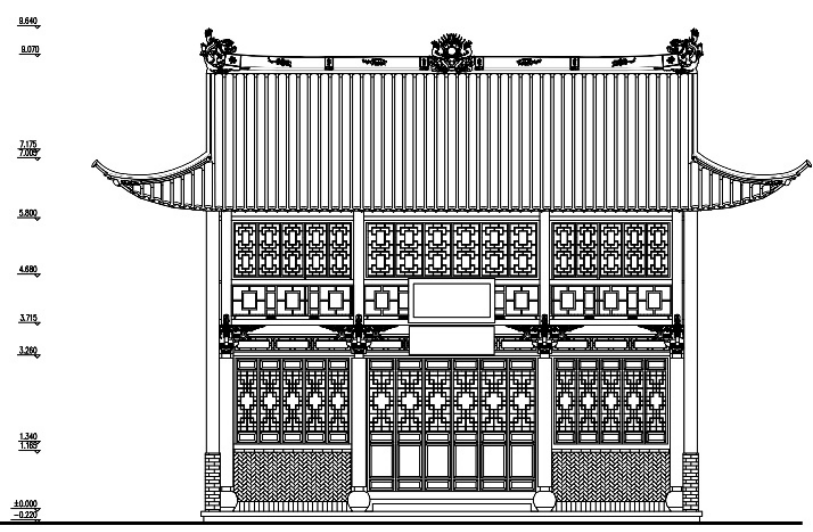

Fig. 6. Facade of Yangfu Temple.

The doors and windows on the facade of shops are rich and exquisite in style, including lattice doors and windows, solid plate doors and windows, movable straight plate doors and windows, etc. A carved door separates difference spaces, but doesn't completely divide them. The windows are also richly patterned, with mullioned, checkered panes and polycentric compositions. There are slate wall, wooden wall and brick wall for the window walls of the building façade ${ }^{[4]}$. 
The details of the Old Street buildings are also very complex and exquisite. The diagonal bracings and wooden windows of the shops are often carved with flowers and auspicious animals. The diagonal bracings use powerful bow shapes, and the brackets are carved with many lifelike fairy stories whose content and style are quite rich with distinctive local characteristics. The traditional Chinese-style architecture shows the style and characteristics of the exquisite Jiangnan room.

\subsection{Architectural Facade Influenced by Western Styles}

Different from the traditional Chinese-style shops and residential buildings, the in-wall shop buildings built after the opening of the port in Haimen Old Street are typical combinations of Chinese and Western buildings. The buildings use Chinese-style spatial patterns while introducing a large number of western-style facade decoration structures and the local elements of the Old Street, which is quite unique. Take Taishan Silver House on the Old Street as an example. Both the vertical and horizontal facades of the building adopt western classical three-section style. The composition and proportion are balanced and harmonious. Pilaster and arch lintels are used to form an arch-column entrance ${ }^{[5]}$. The details of the Silver House facade are decorated with a large number of curves, showing an obvious baroque style. The pediments at the top of the facade are carved with western patterns, and there are also sculptures of flowers, birds and deer with local aesthetic tastes on the walls. In addition, the Ma Tau walls of some of the Old Street buildings remove the warping, and stone carvings of flowers and grasses or auspicious clouds are used instead of tiles of the walls, and the edges and corners of the walls are also curved in a baroque style. The architecture influenced by western style is characterized by a luxuriant, elegant and rhythmic style.

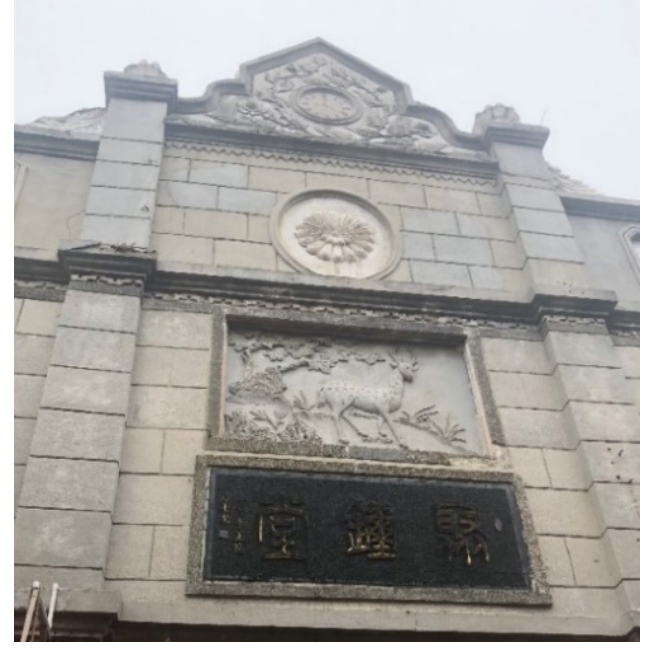

Fig. 7.The decoration of Taishan Silver House

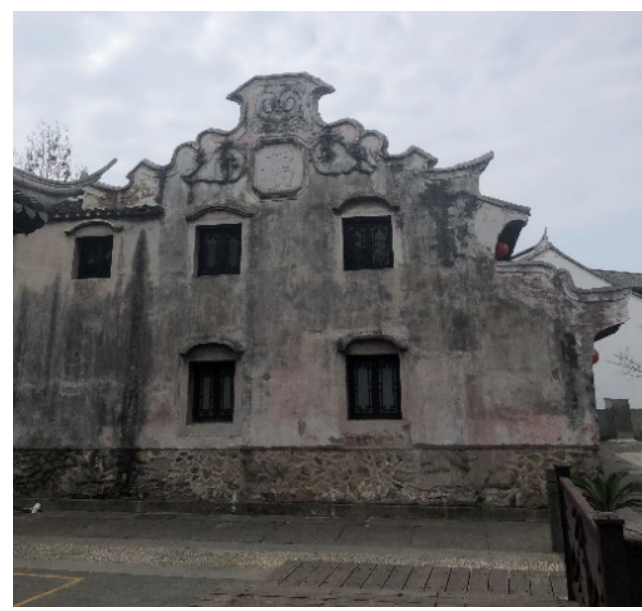

Fig. 8. The Ma Tau wall with western style

\section{Conclusion}

The historical architecture in Haimen Old Street originates from the traditional architecture of eastern Zhejiang Province, which preserves the characteristics of the local architectural space form and style, and shows its profound folk culture. The street space of Haimen Old Street is flexible, with many twists and turns in a pleasant scale. Together with the buildings, it forms the compact and unique urban texture of the old town of Taizhou. The architectural space in the street shows complex diversity, including traditional shops with "upstairs dwelling and downstairs store", small and exquisite trilateral courtyards as well as in-wall shop buildings where double-decked facades form split spaces. These buildings have satisfied the living and working needs of the residents. Meanwhile, the style of the Old Street architecture is a mixture of Chinese and Western characteristics. Most of the building facades near the river embankment are European-style, and most of the buildings near the bridgehead adopt traditional Chinese-style facades. The architectural facades in the middle of the street are more mixed. The street shows the historical changes since the opening of the Haimen port in chronological order.

Both the old buildings in Haimen Old Street and the street itself have high protection value. The core of its protection lies in its original spatial forms and historical and cultural connotations. In the process of repair and protection of the Old Street, it is necessary to tailor the measures and means of control, which should not only take into account the needs of its protection and development, but also highlight the regional characteristics of Taizhou. Only by protecting the historical streets and buildings that have witnessed the urban development can the historical and cultural deposits and characteristics of the city be continued, which is the significance of the study of traditional historic districts.

\section{References}

1. Chen Xuan (2014) Protection and Renewal of the Historic District of Haimen Old Street. Scientific 
Chinese, 19: 54-55.

2. Liu Zhuan (2013) The study of folk architecture in the country of Zhejiang. Master Thesis of Zhejiang Forestry University.

3. Lin Feiao, Lu Mei, Zhang Yi, Xu Zehua, Wang Bo, Shen Jingjing (2020) Research on the Space Type of Modern Port Opening Buildings in Jiaojiang of Taizhou_-Take "Haimen Old Street" as an Example. Journal of Taizhou University, 42: 50-61.

4. Yang Ruyin (2010) Research on the continuity of town traditional blocks and their life culture of Taizhou, Zhejiang. Master Thesis of South China University of Technology.

5. Chang Qing, Wang Hongjun (2001) Keep the memory of "little Shanghai"__Preserve and reuse of "North Xinjiao Street"in Taizhou City. Huazhong Architecture, 19: 88-73. 